\title{
Clinical Features for the Diagnosis of Pediatric Urinary Tract Infections: Systematic Review and Meta-Analysis
}

Hanne A. Boon, MD

Ann Van den Bruel, MD, $P b D^{1,2}$

Thomas Struyf, MSc ${ }^{1}$

Andreas Gillemot, $M D^{1}$

Dominique M. A. Bullens, MD, $\mathrm{PbD}^{3,4}$

Jan Y. Verbakel, $M D, P b D^{1,2}$

'EPI-Centre, Academic Centre for Primary

Care, Katholieke Universiteit Leuven,

Leuven, Belgium

${ }^{2}$ Nuffield Department of Primary Care Health Sciences, University of Oxford, Oxford, United Kingdom

${ }^{3}$ Department of Microbiology, Immunology and Transplantation, Katholieke Universiteit Leuven, Leuven, Belgium

${ }^{4}$ Clinical Division of Pediatrics, Universitair Ziekenhuis Leuven, Leuven, Belgium

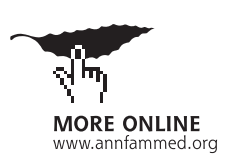

Conflicts of interest: autbors report none.

\section{CORRESPONDING AUTHOR}

Jan Y. Verbakel

Department of Public Health and Primary

Care, Katholieke Universiteit Leuven

Kapucijnenvoer 7,

3000 Leuven, Belgium

jan.verbakel@kuleuven.be

\begin{abstract}
PURPOSE Accurate diagnosis of urinary tract infection in children is essential because children left untreated can experience permanent renal injury. We aimed to assess the diagnostic value of clinical features of pediatric urinary tract infection.
\end{abstract}

METHODS We performed a systematic review and meta-analysis of diagnostic test accuracy studies in ambulatory care. We searched the PubMed, Embase, Web of Science, Cumulative Index to Nursing and Allied Health Literature, Cochrane Central Register of Controlled Trials, Health Technology Assessment, and Database of Abstracts of Reviews of Effects databases from inception to January 27, 2020 for studies reporting $2 \times 2$ diagnostic accuracy data for clinical features compared with urine culture in children aged $<18$ years. For each clinical feature, we calculated likelihood ratios and posttest probabilities of urinary tract infection. To estimate summary parameters, we conducted a bivariate random effects metaanalysis and hierarchical summary receiver operating characteristic analysis.

RESULTS A total of 35 studies ( $N=78,427$ patients) of moderate to high quality were included, providing information on 58 clinical features and 6 prediction rules. Only circumcision (negative likelihood ratio [LR-] 0.24; $95 \% \mathrm{Cl}, 0.08-0.72$; $\mathrm{n}=8$ ), stridor ( $\mathrm{LR}-0.20 ; 95 \% \mathrm{Cl}, 0.05-0.81 ; \mathrm{n}=1)$, and diaper rash ( $(\mathrm{LR}-0.13$; $95 \% \mathrm{Cl}, 0.02-0.92 ; \mathrm{n}=1$ ) were useful for ruling out urinary tract infection. Body temperature or fever duration showed limited diagnostic value (area under the receiver operating characteristic curve $0.61 ; 95 \% \mathrm{Cl}, 0.47-0.73 ; n=16)$. The Diagnosis of Urinary Tract Infection in Young Children score, Gorelick Scale score, and UTIcalc (https://uticalc.pitt.edu) might be useful to identify children eligible for urine sampling.

CONCLUSIONS Few clinical signs and symptoms are useful for diagnosing or ruling out urinary tract infection in children. Clinical prediction rules might be more accurate; however, they should be validated externally. Physicians should not restrict urine sampling to children with unexplained fever or other features suggestive of urinary tract infection.

Ann Fam Med 2021;19:437-446. https://doi.org/10.1370/afm.2684.

\section{INTRODUCTION}

U rinary tract infections (UTIs) are common, especially in very young children. The prevalence of UTI in acutely ill children aged $<5$ years and presenting to the family physician is almost $6 \% .{ }^{1}$ It remains unclear which children should undergo testing for UTI. ${ }^{2}$ In ambulatory care, more than one-half of UTIs in children can be missed at first contact. ${ }^{3,4}$ However, early diagnosis is essential because missed episodes can progress to more serious infections, cause kidney scarring, and might suggest underlying urinary tract malformations. Up to $15 \%$ of children will have permanent renal injury after a first febrile UTI. ${ }^{5}$ This can cause impaired renal growth, recurrent pyelonephritis, renal hypertension, or end-stage renal disease, which can be prevented by prompt antibiotic treatment. ${ }^{6-8}$

Urinary tract infections often remain undetected in children, especially in infants, given their inability to verbally describe symptoms and the difficulty of obtaining a clean urine sample. Neonates with UTI are at 
high risk of developing bacteremia. ${ }^{9}$ For these patients, parents might report fever, irritability, lethargy, vomiting, or poor feeding. ${ }^{10}$ These symptoms also occur with other conditions such as gastroenteritis, tonsillitis, or otitis. For older children, signs are more indicative of a urinary cause such as dysuria or frequency. Current guidelines recommend urine sampling for all young children presenting with an unexplained fever of $>24$ hours or for older children with urinary symptoms. . $^{7,8,11}$

Two systematic reviews, including 1 meta-analysis with searches up to 2007 , have been published. ${ }^{2,12}$ The aim of the present review was to collate the most recent evidence on the diagnostic value of signs and symptoms for pediatric UTI, to assess the probability of UTI before urine sampling.

\section{METHODS}

The study protocol was registered a priori with the Prospero registry (ID CRD42019122174). We report this study according to the Preferred Reporting Items for Systematic Reviews and Meta-Analyses guidelines (Supplemental Appendix 1, https://www.AnnFamMed. org/lookup/suppl/doi:10.1370/afm.2684/-/DC1).

\section{Information Sources and Search Strategy}

Seven electronic databases (PubMed, Embase, Web of Science, Cumulative Index to Nursing and Allied Health Literature, Cochrane Central Register of Controlled Trials, Health Technology Assessment, and Database of Abstracts of Reviews of Effects) were searched from inception for articles on the diagnosis of UTIs in children in ambulatory care (Supplemental Appendix 2, https://www.AnnFamMed.org/lookup/suppl/doi:10.1370/ afm.2684/-/DC1). We conducted the first search on January 16, 2019, which was updated on January 27, 2020. We also checked the references of primary studies and reviews. Five reviewers (H.B., T.S., J.V., A.VdB., A.G.) independently selected studies in pairs, and 2 reviewers (J.V., A.VdB.) resolved conflicts. We deduplicated studies in Endnote X8.2 (Clarivate) and used Covidence (Veritas Health Innovation) for study selection.

\section{Eligibility Criteria}

We included all studies that compared the diagnostic accuracy of clinical features in children $<18$ years of age, with urine culture as the reference standard. Eligible study designs included prospective cross-sectional diagnostic accuracy studies, diagnostic nested case-control studies, and retrospective cohort studies. We only selected studies in the ambulatory care setting, which was defined as outpatient medical care and included family practices, emergency departments, walk-in clinics, health centers, and outpatient hospital departments.
We excluded case-control studies with a differential sampling scheme for cases and controls, reviews, letters, comments, and conference abstracts. We also excluded studies with a total sample size $<50$ children because those studies are prone to selection bias, ${ }_{1}^{13,14}$ and we excluded studies with children from high-risk groups (malnourished, premature). We did not apply any language, country, or time restrictions.

\section{Data Collection}

We extracted data in duplicate (H.B., A.G.) and imported the data to Excel (Microsoft Corp). In the case of incomplete or missing data, we contacted the authors for additional information $(n=34$, of whom 3 authors provided unpublished data) ${ }^{15-17}$ For cells with a zero value, we applied a 0.5 continuity correction.

\section{Risk of Bias and Applicability Assessment}

We assessed the risk of bias with the Quality Assessment of Diagnostic Accuracy Studies tool (QUADAS-2) using RevMan version 5.3 (Cochrane). H.B. assessed the risk of bias and applicability, A.G. checked it independently, and disagreements were resolved during a consensus meeting (H.B., T.S., A.VdB., J.V.). We referred to the urine culture criteria used in the European Association of Urology guideline to assess the reference standard bias. ${ }^{7}$ Studies in which children did not systematically undergo urine sampling were considered at high risk of bias for flow and timing.

\section{Data Analysis}

We used R statistical software version 3.5.1 (R Foundation, mada package version 0.8 .5 ) to calculate the likelihood ratios and posttest probabilities (positive and negative predictive values) of UTI, graphically displaying the change in probability using dumbbell plots (GitHub; Susannah Fleming [https://github.com/susannahf]). ${ }^{18}$ We considered tests to be useful for ruling out UTI if the negative likelihood ratio (LR-) was $\leq 0.25$ (eg, substantially decreasing the likelihood of UTI). Tests were useful as a warning sign or red flag (eg, substantially increasing the likelihood of UTI) if the positive likelihood ratio $\left(\mathrm{LR}+\right.$ ) was $\geq 4 .{ }^{19,20}$ Signs with $\mathrm{LR}+$ from 2 to 4 or LR-from 0.25 to 0.5 were considered amber signs (eg, moderately increasing or decreasing the risk of UTI).

We estimated summary parameters using a bivariate random effects meta-analysis whenever $\geq 3$ primary studies were available. ${ }^{18,21}$ For continuous test results, we conducted a meta-analysis allowing for multiple thresholds per study to be included, while displaying results in a hierarchical summary receiver operating characteristic curve (diagmeta package in $\mathrm{R}$ version 0.4$).{ }^{22}$ 
To assess statistical heterogeneity, we examined forest plots and performed subgroup analyses via metaregression if $\geq 10$ studies were available for this analysis. We performed subgroup analyses for design, population, age, setting, and urine collection method. We also conducted sensitivity analyses to check the robustness of our results whenever we suspected clinical heterogeneity.

\section{RESULTS}

\section{Study Selection}

We screened 10,764 studies by title and abstract, of which we evaluated 331 in full text. Ultimately, we included 35 studies on the accuracy of 58 clinical features ${ }^{4,15-17,23-49}$ and 6 prediction rules (Supplemental Appendix 3, https://www.AnnFamMed.org/lookup/ suppl/doi:10.1370/afm.2684/-/DC1). 15,16,41,42,50-53 None of these studies reported on pyelonephritis or bacteremia separately but rather reported on UTI as a composite outcome.

\section{Study Characteristics}

Study characteristics are shown in Supplemental Appendix 4 (https://www.AnnFamMed.org/lookup/suppl/ doi:10.1370/afm.2684/-/DC1). The total number of included patients was 78,427 , ranging from 75 to 15,801 patients. Twenty-four studies were conducted at the emergency department.* Other settings included health centers $(\mathrm{n}=3)_{,}{ }^{26,28,35}$ hospital outpatient departments $(\mathrm{n}=2){ }_{1}^{34,38}$ family practices and emergency departments $(\mathrm{n}=4)_{1}, 15,41,48$ and pediatricians' offices $(\mathrm{n}=1){ }^{37}$

Authors used different inclusion criteria, and UTI prevalence ranged from $1.3 \%$ to $63.5 \%,{ }^{15,38}$ with a median of $10 \%$. Most studies included children aged $<5$ years $(\mathrm{n}=24){ }^{\dagger}{ }^{\dagger}$ Two studies included only acutely ill children, ${ }^{4,41}$ whereas 12 studies included only febrile children. Four studies included children with unexplained fever, ${ }_{1}^{17,39,50,52} 8$ studies included children with features of UTI, $15,26,31,32,34,38,46,48$ and 9 studies included children for whom urine samples were obtained at the physician's discretion. ${ }^{23-25,30,33,45,47,49,51}$

Most studies used catheterization ( $\mathrm{n}=23)$, suprapubic aspiration $(n=17)$, or midstream catch $(n=14)$ to sample urine, and fewer studies used clean catch $(n=7)$, bag specimens $(n=5)$, or diaper pads $(n=2)$. All studies used urine culture as the reference standard.

\section{Risk of Bias and Applicability}

The risk-of-bias assessment is shown in Supplemental Appendix 5 (https://www.AnnFamMed.org/lookup/

*References $16,17,23-25,27,29,30,32,33,36,39,40,42-47,49-53$

†References 4, 15-17, 24, 25, 27-30, 35-37, 39, 40, 42-46, 50-53.

¥References $16,27-29,35-37,40,42-44,53$.
suppl/doi:10.1370/afm.2684/-/DC1). The overall risk of bias was moderate to high. The high risk of selection bias was caused by retrospective sampling $(\mathrm{n}=$ 9) ${ }_{1}^{16,24,25,33,44,45,47,51,52}$ recruiting a convenience or nonconsecutive sample $(\mathrm{n}=5),{ }^{23,27,30,40,42}$ and including a narrow spectrum of patients $(n=4) .{ }^{26,31,46,48}$ Studies were considered at high risk of bias for reference standard when the positivity threshold was not adapted to the sampling method $(\mathrm{n}=5)^{17,27,32,36,52}$ or was lower than the recommended threshold $(\mathrm{n}=3) .{ }^{26,31,47} \mathrm{~A}$ high risk of bias for flow and timing was assumed when a urine sample was obtained from a small proportion of included children $(n=3)^{41,43,53}$ or for inappropriate exclusions from the analyses $(n=2){ }^{26,40}$

\section{Diagnostic Accuracy of Signs and Symptoms}

Likelihood ratios and posttest disease probabilities are shown in Figure 1 and Supplemental Appendices 4 and 5 (https://www.AnnFamMed.org/lookup/suppl/ doi:10.1370/afm.2684/-/DC1). Summary estimates are shown in Table 1. Because we suspected low applicability to our research question by the study of Pylkkänen et $\mathrm{al}_{1}{ }^{38}$ we excluded that study from the meta-analysis.

\section{(1) Ruling out UTI}

Being circumcised (LR- 0.24; $95 \%$ CI, 0.08-0.72; $\mathrm{n}=8), 15,16,30,34,37,39,42,46$ the presence of stridor (LR- 0.20 ; $95 \% \mathrm{CI}, 0.05-0.81),{ }^{43}$ and the presence of diaper rash (LR- $0.13 ; 95 \%$ CI, 0.02-0.92) $)^{15}$ substantially decreased the likelihood of UTI.

In febrile children, finding an apparent source of infection (LR- $0.35 ; 95 \% \mathrm{CI}, 0.22-0.55)$ decreased the probability of UTI, however, this was not useful for ruling out UTI by itself (ie, the LR- was not $\leq 0.25) \cdot{ }^{16,29,39,43}$

\section{(2) Red flags for UTI}

Cloudy urine ( $\mathrm{LR}+4.55 ; 95 \% \mathrm{Cl}, 3.73-5.56$; $\mathrm{n}=4)^{15,23,31,32}$ and malodorous urine ( $\mathrm{LR}+4.13 ; 95 \% \mathrm{CI}$, 2.27-7.49; $\mathrm{n}=4)^{15,16,26,46}$ were red flags for UTI. Suprapubic tenderness, loin tenderness, capillary refill time $>3$ seconds, and no fluid intake were useful for ruling in UTI on the basis of 1 study each (LR+ 7.94, 95\% CI, 3.18-19.86; LR+ 16.63, 95\% CI, 3.30-83.86; LR+ 4.80, 95\% CI, 2.16-10.60; and LR+ 4.39, 95\% CI, 1.72-11.20, respectively). ${ }^{15,43}$

With regard to hematuria, it was not possible to draw firm conclusions because of heterogeneity, although specificity appeared to be high (Table 1 ). In 1 low-prevalence study, the LR+ was $6.27(95 \% \mathrm{CI}$, 1.47-26.71), whereby hematuria might be considered a red flag. ${ }^{15}$

Dysuria $(\mathrm{LR}+3.28 ; 95 \% \mathrm{CI}, 2.22-4.86$; $\mathrm{n}=7)^{4,15,26,28,33,35,46}$ and frequency (LR+ 2.21; $95 \%$ CI, $1.78-2.75 ; \mathrm{n}=4)^{4,15,26,33}$ moderately increased the 
probability of UTI (ie, LR+ 2-4), as did darker urine, bed wetting when previously dry, previous UTI, and genitourinary abnormalities.

The following signs did not change the posttest probability and therefore might have no diagnostic value for UTI: diarrhea, vomiting, abdominal pain, poor feeding, poor weight gain, irritability, abnormal appearance, and shivering.

Figure 1a. Likelihood ratios and posttest disease probabilities for urinary symptoms (dumbbell plots).

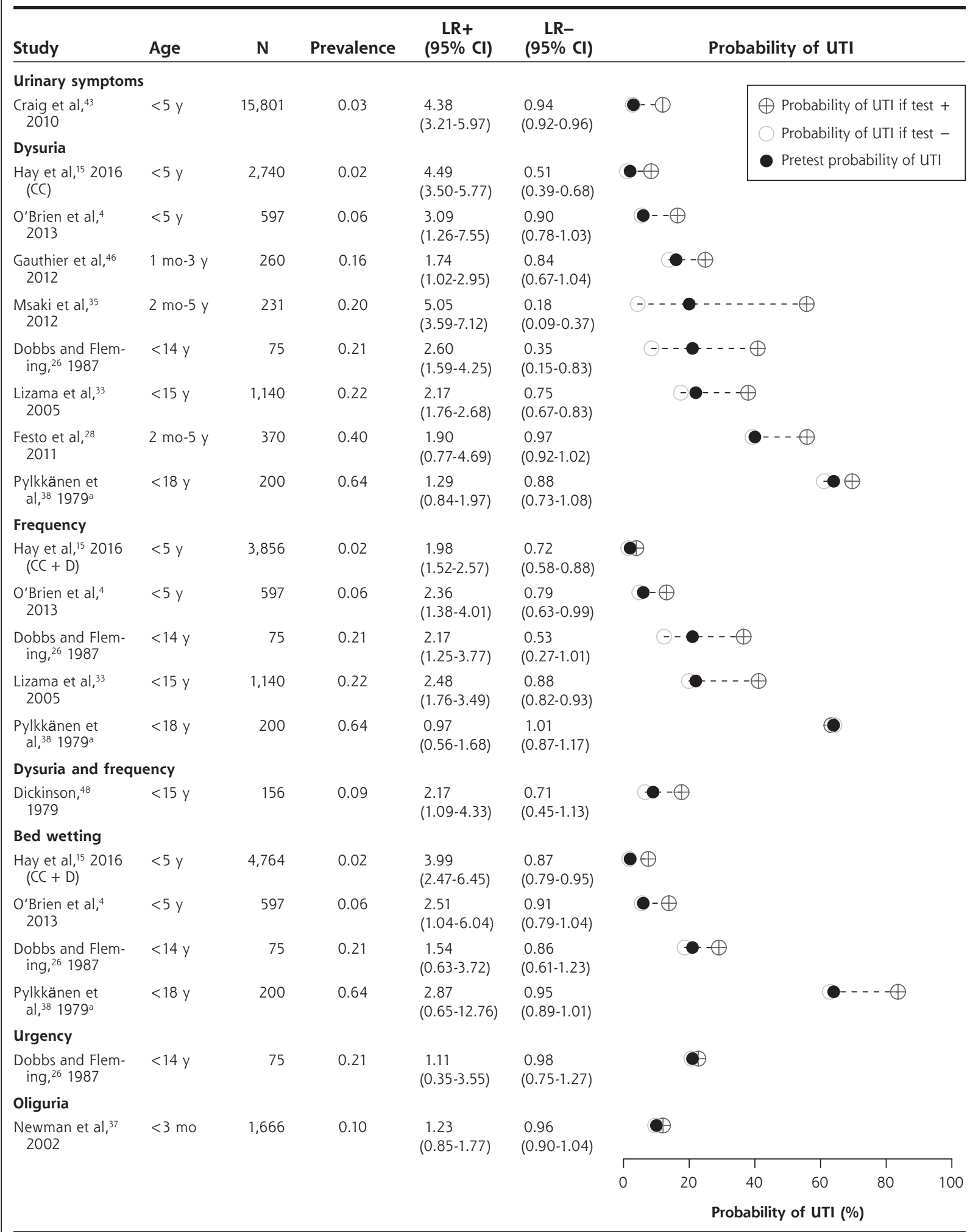


Figure 1b. Likelihood ratios and posttest disease probabilities for urine appearance (dumbbell plots).

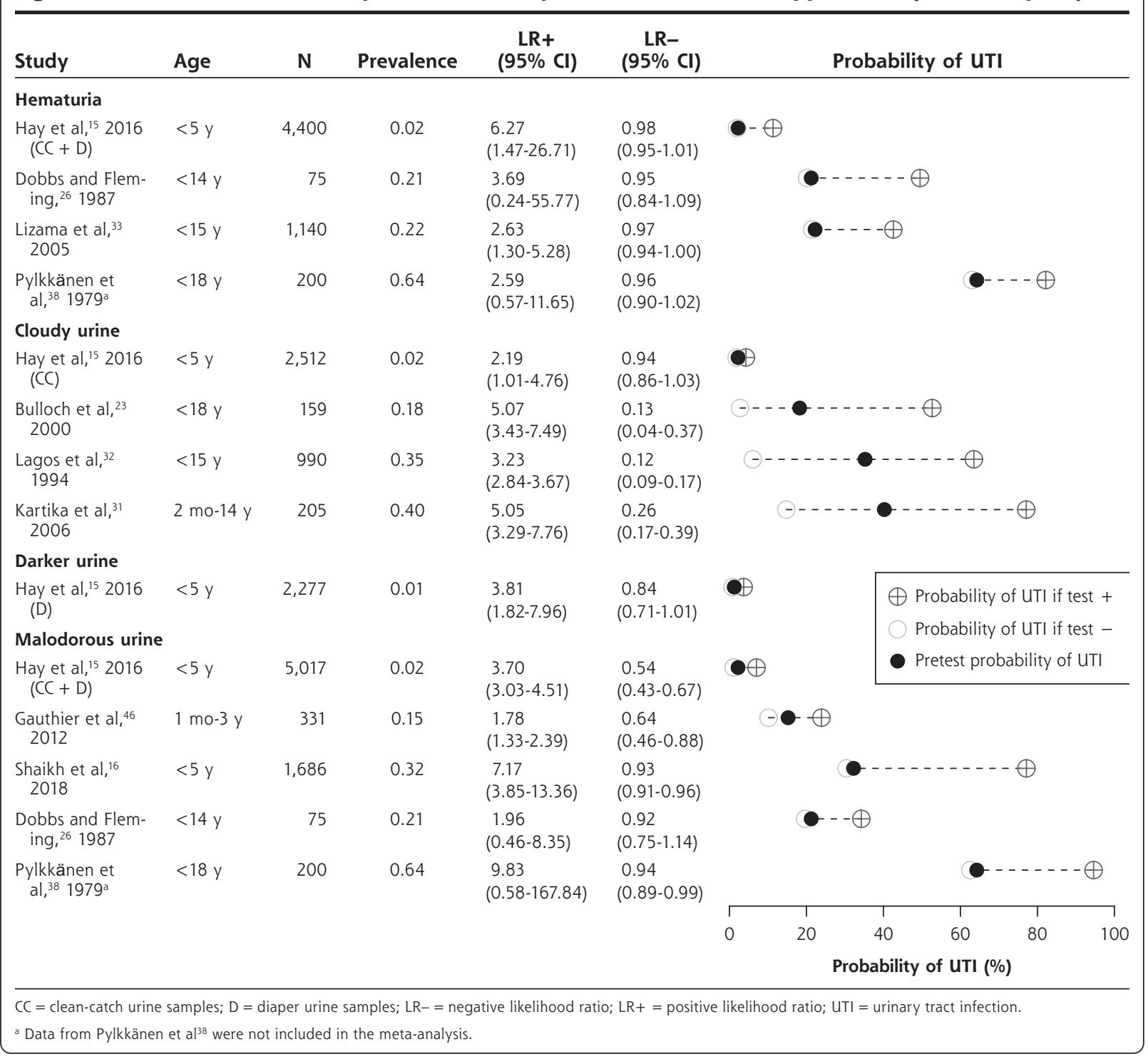

(3) Body temperature and fever duration

Body temperature was not associated with UTI (area under the receiver operating characteristic curve 0.61 ; 95\% CI, 0.47-0.73) on the basis of 16 studies* (Figure 2). In addition, fever duration $>24,48$, or 72 hours or 5 days was not useful on the basis of 1 study each (Supplemental Appendix 6).

\section{Diagnostic Accuracy of Prediction Rules}

An overview of the prediction rules is provided in Figure 3 and Supplemental Appendix 7 (https://www. AnnFamMed.org/lookup/suppl/doi:10.1370/afm.2684/-/ DC1). Seven studies identified with the initial search strategy reported on the diagnostic accuracy of a combination of signs and symptoms for UTI, of which 3 studies were included in the meta-analyses for clinical features. ${ }^{15,16,42}$ A Diagnosis of Urinary Tract Infection in Young Children (DUTY) clean-catch score $<1$ point was useful for ruling out UTI (LR- $0.05 ; 95 \%$ $\mathrm{CI}, 0-0.82)$ in children aged $<5$ years. ${ }^{15}$ In girls aged $<2$ years with unexplained fever, the Gorelick Scale score was useful for ruling out UTI when $<2$ of 5 variables were present (LR- 0.11; 95\% CI, 0.01-0.81). ${ }^{51}$ Using the UTIcalc score (https://uticalc.pitt.edu), the probability of UTI decreased to $<2 \%$ in all circumcised boys except non-African American infants with unexplained fever. For girls and circumcised boys, the probability of UTI decreased to $<2 \%$ if none of the following variables were present: temperature $\geq 39^{\circ} \mathrm{C}$, no source of fever, non-African American (LR- 0.05; 
Figure 1c. Likelihood ratios and posttest disease probabilities for clinical examination features (dumbbell plots).

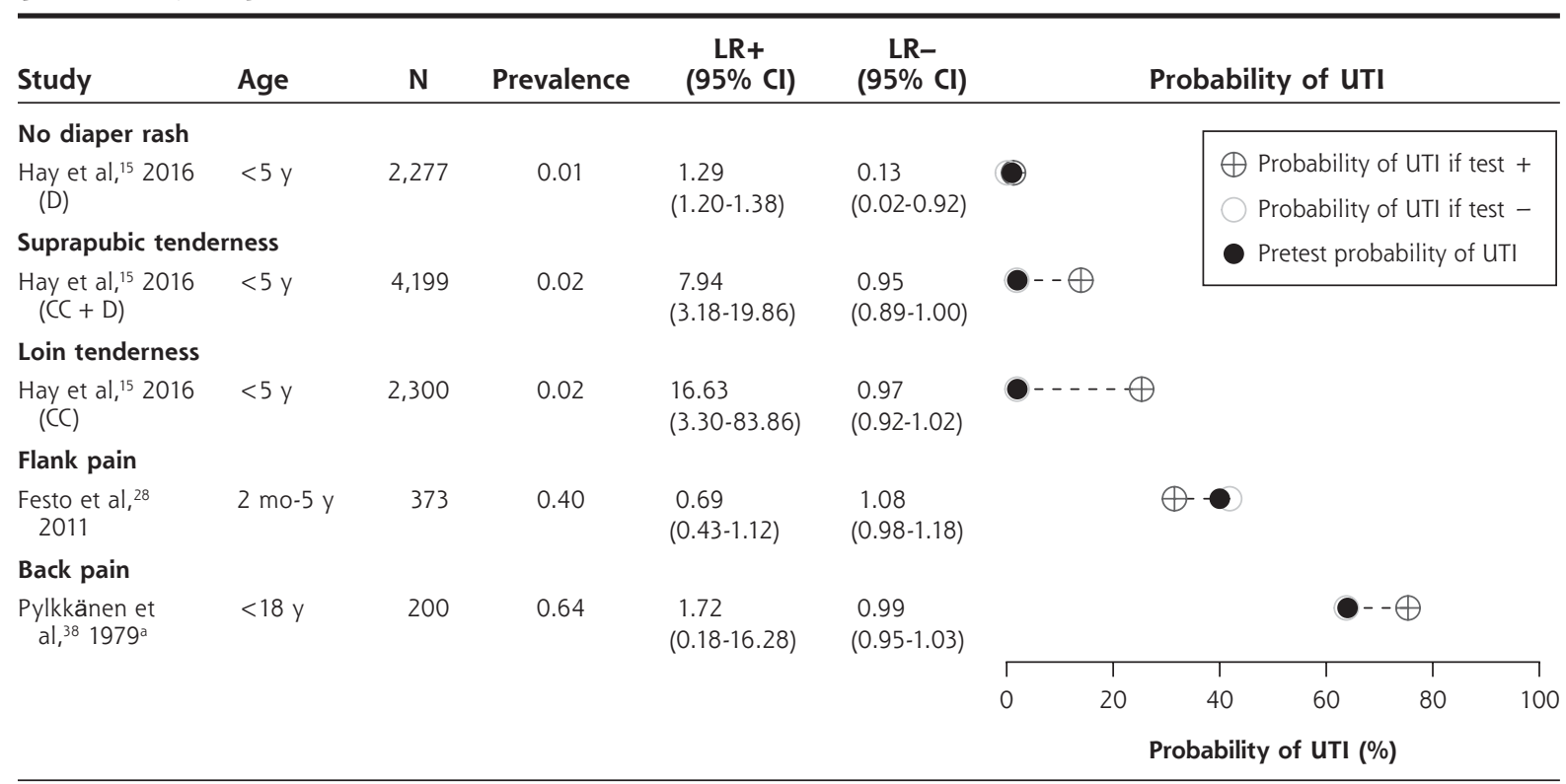

$\mathrm{CC}=$ clean-catch urine samples; $\mathrm{D}=$ diaper urine samples; $\mathrm{LR}-=$ negative likelihood ratio; $\mathrm{LR}+=$ positive likelihood ratio; $\mathrm{UTI}=$ urinary tract infection.

a Data from Pylkkänen et $\mathrm{l}^{38}$ were not included in the meta-analysis.

Table 1. Diagnostic Accuracy of Clinical Features for Urinary Tract Infection (Summary Estimates)

\begin{tabular}{|c|c|c|c|c|c|c|}
\hline Clinical Feature & $\begin{array}{c}\text { No. } \\
\text { Studies }^{\mathrm{a}}\end{array}$ & $\mathbf{N}$ & $\begin{array}{l}\text { Summary } \\
\text { Sensitivity, } \\
\%(95 \% \mathrm{Cl})\end{array}$ & $\begin{array}{c}\text { Summary } \\
\text { Specificity, \% } \\
(95 \% \mathrm{Cl})\end{array}$ & $\begin{array}{c}\text { Summary LR+ } \\
(95 \% \mathrm{Cl})\end{array}$ & $\begin{array}{c}\text { Summary } \\
\text { LR- }(95 \% \mathrm{CI})\end{array}$ \\
\hline \multicolumn{7}{|c|}{ Red Flags $(L R+\geq 4)$ or Features $(L R-\leq 0.25)$} \\
\hline Hematuria & 3 & 5,615 & $4(2-8)$ & $99(97-100)$ & $4.23(1.71-10.44)$ & $0.97(0.94-1.00)$ \\
\hline Cloudy urine & 4 & 3,866 & $69(30-92)$ & $85(72-92)$ & $4.55(3.73-5.56)$ & $0.36(0.13-1.02)$ \\
\hline Malodorous urine & 4 & 7,109 & $31(12-59)$ & $93(75-98)$ & $4.13(2.27-7.49)$ & $0.75(0.58-0.98)$ \\
\hline No circumcision & 8 & 6,712 & $88(52-98)$ & $52(23-80)$ & $1.81(1.15-2.87)$ & $0.24(0.08-0.72)$ \\
\hline \multicolumn{7}{|c|}{ Amber Signs (LR+ 2-4 or LR- $0.25-0.5)$} \\
\hline Dysuria & 7 & 5,413 & $40(19-66)$ & $88(80-93)$ & $3.28(2.22-4.86)$ & $0.68(0.47-1.00)$ \\
\hline Frequency & 4 & 5,668 & $36(22-53)$ & $84(74-90)$ & $2.21(1.78-2.75)$ & $0.76(0.65-0.90)$ \\
\hline Bed wetting & 3 & 5,436 & $21(12-32)$ & $92(84-97)$ & $2.70(1.46-4.99)$ & $0.86(0.78-0.95)$ \\
\hline Previous UTI & 7 & 7,546 & $15(9-24)$ & $94(88-97)$ & $2.31(1.73-3.10)$ & $0.91(0.86-0.96)$ \\
\hline No source of infection & 4 & 20,964 & $84(74-91)$ & $45(18-75)$ & $1.53(0.92-2.54)$ & $0.35(0.22-0.55)$ \\
\hline \multicolumn{7}{|c|}{ Signs With LR+ $<2$ or LR- $>0.5$} \\
\hline Diarrhea & 7 & 24,640 & $20(12-30)$ & $78(73-83)$ & $0.91(0.68-1.22)$ & $1.03(0.96-1.10)$ \\
\hline Vomiting & 7 & 10,505 & $27(19-38)$ & $69(61-76)$ & $0.89(0.74-1.06)$ & $1.05(1.00-1.12)$ \\
\hline Abdominal pain & 6 & 5,397 & $29(14-51)$ & $84(64-94)$ & $1.86(0.82-4.22)$ & $0.84(0.67-1.07)$ \\
\hline No cough & 4 & 20,946 & $81(33-97)$ & $32(7-76)$ & $1.19(0.93-1.52)$ & $0.61(0.34-1.07)$ \\
\hline Irritability & 5 & 5,395 & $15(4-48)$ & $85(63-95)$ & $1.00(0.67-1.48)$ & $1.00(0.93-1.07)$ \\
\hline Abnormal appearance & 4 & 26,525 & $36(17-60)$ & $70(50-85)$ & $1.21(1.02-1.44)$ & $0.91(0.80-1.04)$ \\
\hline Age $<12$ mo & 3 & 2,110 & $67(47-83)$ & $41(28-55)$ & $1.13(1.02-1.26)$ & $0.81(0.61-1.07)$ \\
\hline Female & 15 & 47,351 & $66(57-74)$ & $47(42-52)$ & $1.24(1.11-1.39)$ & $0.73(0.58-0.91)$ \\
\hline White & 10 & 42,456 & $50(34-65)$ & $58(42-73)$ & $1.18(0.96-1.46)$ & $0.87(0.73-1.04)$ \\
\hline Hispanic & 7 & 34,074 & $12(4-32)$ & 89 (76-95) & $1.03(0.74-1.44)$ & $1.00(0.95-1.05)$ \\
\hline Asian & 5 & 24,623 & $5(4-7)$ & $96(95-97)$ & $1.42(1.09-1.86)$ & $0.98(0.97-1.00)$ \\
\hline Non-African American & 10 & 42,397 & $85(76-91)$ & $27(14-45)$ & $1.17(1.02-1.33)$ & $0.55(0.48-0.63)$ \\
\hline
\end{tabular}


95\% CI, 0-0.79). ${ }^{16}$ In addition, a DUTY clean-catch or diaper pad score $\geq 5$ points was useful as a red flag (LR+ 9.55, 95\% CI, 7.14-12.78 and $\mathrm{LR}+4.13,95 \% \mathrm{CI}$, 2.91-5.87, respectively). ${ }^{15}$ The Yale Observation Scale and the National Institute for Health and Care Excellence traffic light system were not useful for ruling in or out UTI in children aged $<3$ months or $<6$ years, respectively. ${ }^{42,52}$

\section{Additional Analyses}

Subgroup analyses via metaregression were only possible for ethnicity and sex. For other signs and symptoms with variable LR values (Supplemental Appendix 8, https://www.AnnFamMed.org/lookup/suppl/doi:10.1370/ afm.2684///DC1), we performed sensitivity analyses to explore the effect of age, setting, inclusion criteria, and reference standard (Supplemental Appendix 9, https:// www.AnnFamMed.org/lookup/suppl/doi:10.1370/ afm.2684///DC1). Exclusion of studies of children aged $>5$ years, those with a suboptimal reference standard (positivity threshold lower than recommended or urine collection method unclear), or those in emergency department or nonemergency department settings did not affect LR values. With regard to malodorous urine, exclusion of 1 retrospective study ${ }^{16}$ gave an $\mathrm{LR}+$ of $2.90(95 \% \mathrm{CI}$, $1.61-5.22 ; \mathrm{n}=3)$ in children aged $<5$ years, assuming this feature might be considered an amber sign instead of a red flag on the basis of higher-quality studies.

\section{DISCUSSION}

\section{Summary}

Only 3 features (circumcision, stridor, and diaper rash) appeared to decrease the probability of UTI sufficiently, whereas cloudy or malodorous urine, hematuria, no fluid intake, suprapubic tenderness, and loin tenderness could be useful as red flags.

Urgency, frequency, dysuria, bed wetting, and history of UTI moderately increased the probability of UTI in children.

Guidelines recommend obtaining a urine sample from children with unexplained fever or other symptoms suggestive of UTI. The present study suggests that this sampling strategy might be inadequate because only few clinical features increased or decreased the likelihood of UTI in children, and the absence of unexplained fever did not rule out UTI (LR- 0.35).

Combining signs and symptoms in a clinical prediction rule, such as with the UTIcalc, DUTY cleancatch, or Gorelick Scale score, might be more accurate to rule out UTI in ambulatory care; however, they require a greater proportion of children to be tested with urine sampling compared to current guidelines. ${ }^{6-8}$ Furthermore, these decision rules should be validated externally.

\section{Strengths and Limitations}

The main strengths of the present study were the comprehensive search strategy and the meta-analysis taking into account heterogeneity and multiple thresholds.

We observed between-study heterogeneity, which could be seen as a limitation of the study. Most studies
Figure 2. HSROC curve analysis of body temperature for urinary tract infection.

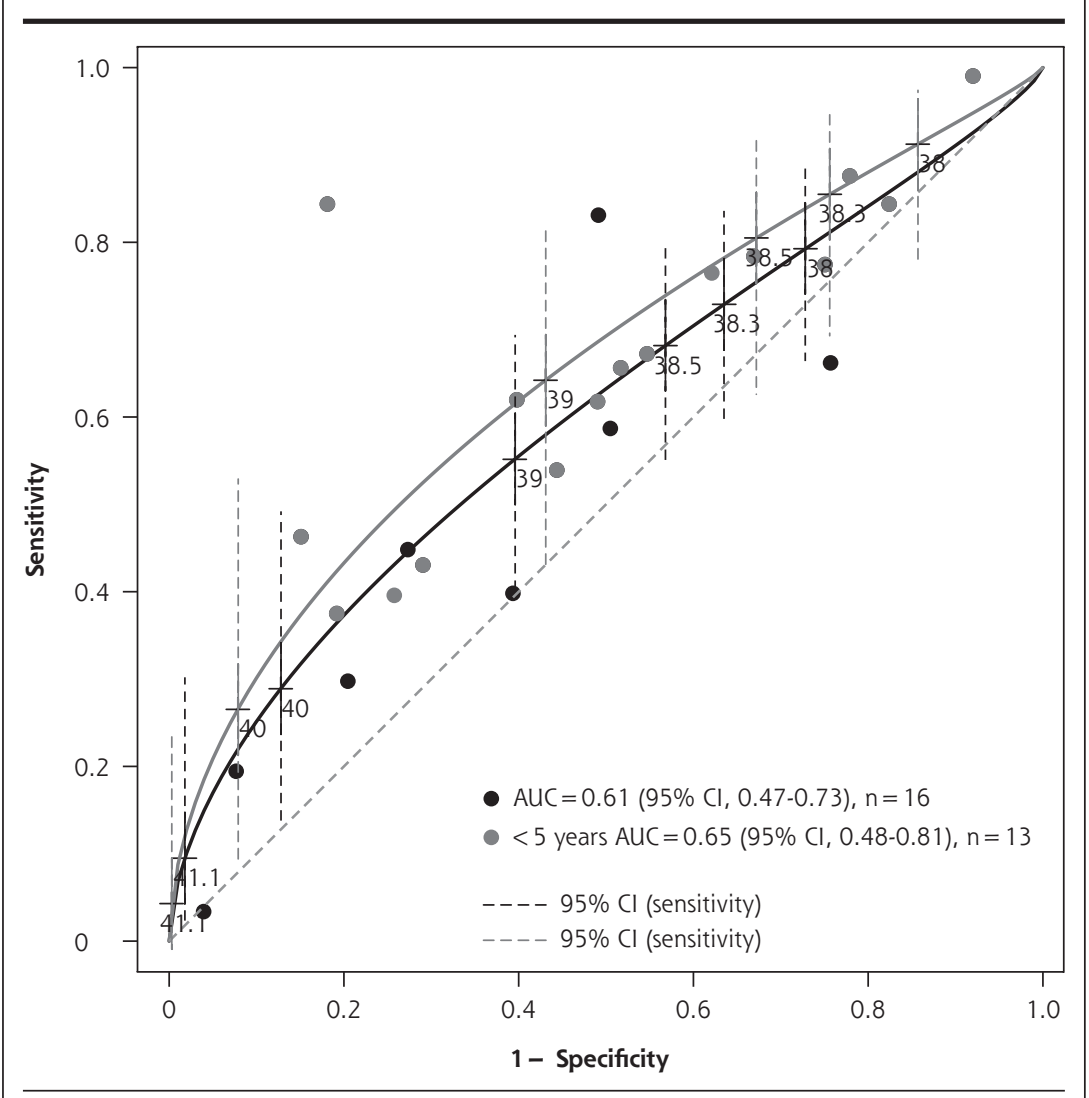

$\mathrm{AUC}=$ area under the ROC curve; $\mathrm{HSROC}=$ hierarchical summary receiver operating characteristic; $\mathrm{ROC}=$ receiver operating characteristic.

Note: HSROC curve analysis of body temperature for urinary tract infection in children, showing sensitivity vs 1 -specificity at each threshold. The thresholds provided in primary studies are indicated on the graph. The Cls of the estimates are indicated as dashed lines. (Sample size $=43,570$, including data from 16 primary studies). 
reporting on cloudy and malodorous urine are from highprevalence settings ( $>20 \%$ ). Only 1 study from a low-prevalence setting (2\%) reported an $\mathrm{LR}+$ of 2.19 (95\% CI, 1.01-4.74) and an $\mathrm{LR}+$ of 3.70 (95\% CI, 3.03-4.51) for cloudy and malodorous urine, respectively. ${ }^{15}$ With regard to dysuria, abdominal pain, and no source of fever, the LR values varied between studies, and sensitivity analyses revealed no effect of age, setting, or inclusion criteria.

\section{Comparison With Existing Knowledge}

A systematic review by Whiting et $\mathrm{al}^{2}$ identified 6 studies describing the accuracy of 5 clinical features and the Gorelick Scale score. Hay et a $1^{15,54}$ provided updates in 2011 and 2016, including 13 ambulatory care studies. We further explored the summary estimates for 58 clinical features in total and found 5 additional prediction rules, of which 3 might be useful for ruling out UTI.

A systematic review and metaanalysis by Shaikh et a ${ }^{12}$ found 12 studies. They suggested that body temperature $\geq 40^{\circ} \mathrm{C}$ might be useful as a red flag ( $L R+$ range 3.2-3.3; $\mathrm{n}=2$ ). We found 12 additional studies, which we included in a hierarchical summary receiver operating characteristic analysis, providing results at variable thresholds.

Narrative reviews described abdominal pain, irritability, and vomiting as important features; however, our results showed that these symptoms might have no value in children (Table 1, Supplemental Appendix 6), 9,10,55

\section{Implications for Practice}

The present study suggests that broader sampling strategies might be more appropriate to identify pediatric UTI at an early stage. Novel urine collection methods and reliable tests are urgently needed for

a Derivation studies.
Figure 3. Original ROC curve analysis of clinical prediction rules for urinary tract infections.

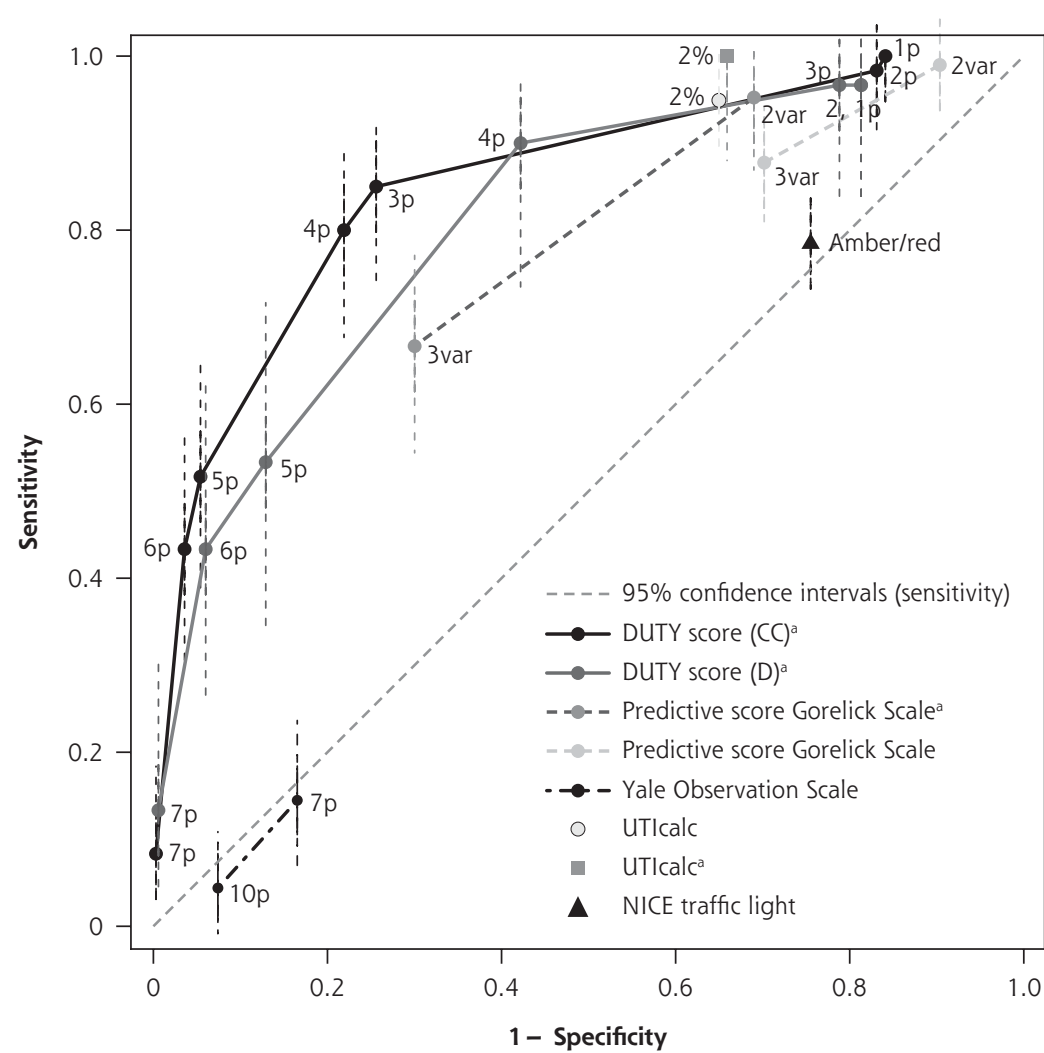

\begin{tabular}{|c|c|}
\hline Prediction Rule & Variables \\
\hline $\begin{array}{l}\text { DUTY score, clean } \\
\text { catch (CC) }\end{array}$ & $\begin{array}{l}\text { Pain while urinating }(2 p) \text {, malodorous urine }(2 p) \text {, history of UTI } \\
(1 p) \text {, absence of cough }(2 p) \text {, severe illness }{ }^{b}(2 p)\end{array}$ \\
\hline DUTY score, diaper (D) & $\begin{array}{l}\text { Female }(1 p) \text {, malodorous urine }(2 p) \text {, darker urine }(1 p) \text {, absence of } \\
\text { diaper rash }(3 p)\end{array}$ \\
\hline UTIcalc & $\begin{array}{l}\text { Age }<12 \text { mo, temperature } \geq 39^{\circ} \mathrm{C} \text {, non-African American, female, } \\
\text { uncircumcised male, other fever source }\end{array}$ \\
\hline Gorelick Scale & $\begin{array}{l}\text { Age }<12 \text { mo, temperature } \geq 39^{\circ} \mathrm{C} \text {, White, fever } \geq 2 \text { days, absence } \\
\text { of other fever source }\end{array}$ \\
\hline Yale Observation Scale & $\begin{array}{l}\text { Quality of cry, reaction to parents, arousability, skin color, hydra- } \\
\text { tion, social response }\end{array}$ \\
\hline NICE traffic light & Color, activity, respiratory, circulation and hydration, other \\
\hline
\end{tabular}

$\mathrm{CC}=$ clean-catch urine samples; $\mathrm{D}=$ diaper urine samples; DUTY = Diagnosis of Urinary Tract Infection in Young Children; NICE = National Institute for Health and Care Excellence; $p=$ points; $R O C=$ receiver operating characteristic; UTI = urinary tract infection; UTIcalc = UTI Calculator; var = variable.

Note: ROC curve analysis showing sensitivity vs 1-specificity at each threshold. The cutoff for a positive rule is shown next to each point on the graph. Each symbol represents the diagnostic test accuracy of 1 prediction rule for urinary tract infection in children.

b Score $\geq 6$ on Clinical Global Impression - Severity scale (0-10). infants and children to allow for the ruling out of UTI in ambulatory care. In countries where the circumcision rate is high among boys, the presence of circumcision can aid in ruling out UTI if no other UTI features are present. The Yale Observation Scale and National Institute for Health and Care Excellence traffic light system should not be used for UTI. 
New studies in which urine is collected systematically from acutely ill children in ambulatory care should also focus on validating existing prediction rules to rule out UTI and to define which children require urine sampling.

In conclusion, the present meta-analyses confirm that few clinical features are useful for diagnosing or ruling out UTI without further urine analysis. Signs and symptoms combined in a clinical prediction rule, such as with the DUTY or UTIcalc score, might increase accuracy for ruling out $\mathrm{UTI}_{i}$ however, these should be validated externally. Urine sampling should not be restricted to children with unexplained fever or UTI features and should be applied more broadly in ambulatory care, given that appropriate sampling techniques are available.

To read or post commentaries in response to this article, go to https://www. AnnFamMed.org/content/19/5/437/tab-e-letters.

Key words: primary care issues; urinary tract problems; special population: children/infants; special population: adolescents; quantitative methods: meta-analysis; diagnostic testing

Submitted July 24, 2020; submitted, revised, November 23, 2020; accepted December 3, 2020.

Author contributions: H.B., J.V., T.S., D.B., and A.VdB. designed the review. J.V. coordinated the review. H.B., T.S., and J.V. designed the search strategy. H.B. undertook the searches, and H.B., J.V., T.S., A.VdB., and A.G. screened the search results against eligibility criteria. J.V. and A.VdB. resolved conflicts. H.B. and A.G. appraised quality. H.B. and A.G. extracted the data, and H.B. analyzed the data. H.B., T.S., A.VdB., J.V., and D.B. interpreted the data. D.B. provided general advice on the review. J.V. secured funding for the review. J.V. is the guarantor of this manuscript. All authors reviewed the final manuscript. H.B. attests that all listed authors meet authorship criteria and that no others meeting the criteria have been omitted.

Funding support: This study did not receive any specific funding. H.B. is funded by a Katholieke Universiteit Leuven Starting Grant (No. ERXD5331-STG/18/008). D.B. is a recipient of a Senior Clinical Investigator Fellowship from the Research Foundation Flanders (FWO). The financial sponsor played no role in the design, execution, analysis, or interpretation of the data or in the writing of the study.

Disclaimer: J.V. affirms that the manuscript is an honest, accurate, and transparent account of the study being reported; that no important aspects of the study have been omitted; and that any discrepancies from the study as planned (and, if relevant, registered) have been explained.

Data sharing: Full data sets can be obtained from the corresponding author at hanne.boon@kuleuven.be.

Previous presentation: General Practice Research on Infections Network meeting 2019; September 25-26, 2019; Leuven, Belgium.

Acknowledgments: The authors wish to thank Thomas Vandendriessche, Eline Vancoppenolle and Krizia Tuand, the biomedical reference librarians of the KU Leuven Libraries - 2Bergen - Learning Centre Désiré Collen (Leuven, Belgium), for their help in conducting the systematic literature search. Additionally, we would like to thank Dr Schwarzer for providing statistical advice and authors for sharing nonpublished data: Professor Dr Hay, Professor Dr Shaikh, Professor Dr Waterfield, Dr Velasco, Professor Dr Oostenbrink, Professor Dr Andreola, Dr Bressan, and Dr Hildenwall.
Supplemental materials: Available at https://www.AnnFamMed. org/lookup/suppl/doi:10.1370/afm.2684/-DC1.

\section{References}

1. Butler CC, O'Brien K, Pickles T, et al; DUTY study team. Childhood urinary tract infection in primary care: a prospective observational study of prevalence, diagnosis, treatment, and recovery. $\mathrm{Br} J \mathrm{Gen}$ Pract. 2015;65(633):e217-e223.

2. Whiting $P$, Westwood $M$, Bojke $L$, et al. Clinical effectiveness and cost-effectiveness of tests for the diagnosis and investigation of urinary tract infection in children: a systematic review and economic model. Health Technol Assess. 2006;10(36):iii-iv, xi-xiii, 1-154.

3. Coulthard MG, Vernon SJ, Lambert HJ, Matthews JNS. A nurse led education and direct access service for the management of urinary tract infections in children: prospective controlled trial. BMJ. 2003; 327(7416):656.

4. O'Brien K, Edwards A, Hood K, Butler CC. Prevalence of urinary tract infection in acutely unwell children in general practice: a prospective study with systematic urine sampling. Br J Gen Pract. 2013; 63(607):e156-e164.

5. Shaikh N, Ewing AL, Bhatnagar S, Hoberman A. Risk of renal scarring in children with a first urinary tract infection: a systematic review. Pediatrics. 2010;126(6):1084-1091.

6. Roberts KB. Revised AAP guideline on UTI in febrile infants and young children. Am Fam Physician. 2012;86(10):940-946.

7. Stein R, Dogan HS, Hoebeke P, et al; European Association of Urology; European Society for Pediatric Urology. Urinary tract infections in children: EAU/ESPU guidelines. Eur Urol. 2015;67(3):546-558.

8. National Institute for Health and Care Excellence (NICE). Clinical guideline CG54. Urinary tract infection in under 16s: diagnosis and management. Published Aug 2007. Updated Oct 2018. Accessed Jan 2020. https://www.nice.org.uk/guidance/cg54

9. Leung AKC, Wong AHC, Leung AAM, Hon KL. Urinary tract infection in children. Recent Pat Inflamm Allergy Drug Discov. 2019;13(1): 2-18.

10. Kaufman J, Temple-Smith M, Sanci L. Urinary tract infections in children: an overview of diagnosis and management. BMJ Paediatr Open. 2019;3(1):e000487.

11. Shah L, Mandlik N, Kumar P, Andaya S, Patamasucon P. Adherence to AAP practice guidelines for urinary tract infections at our teaching institution. Clin Pediatr (Phila). 2008;47(9):861-864.

12. Shaikh N, Morone NE, Lopez J, et al. Does this child have a urinary tract infection? JAMA. 2007;298(24):2895-2904.

13. Obuchowski NA. Sample size calculations in studies of test accuracy. Stat Methods Med Res. 1998;7(4):371-392.

14. Knottnerus JA, Buntinx F. The Evidence Base of Clinical Diagnosis: Theory and Methods of Diagnostic Research. $2^{\text {nd }}$ ed. Wiley-Blackwell; 2009.

15. Hay AD, Birnie K, Busby J, et al. The Diagnosis of Urinary Tract infection in Young children (DUTY): a diagnostic prospective observational study to derive and validate a clinical algorithm for the diagnosis of urinary tract infection in children presenting to primary care with an acute illness. Health Technol Assess. 2016;20(51):1-294.

16. Shaikh N, Hoberman A, Hum SW, et al. Development and validation of a calculator for estimating the probability of urinary tract infection in young febrile children. JAMA Pediatr. 2018;172(6): 550-556.

17. Velasco R, Benito H, Mozun R, et al; Group for the Study of Febrile Infant of the RiSEUP-SPERG Network. Using a urine dipstick to identify a positive urine culture in young febrile infants is as effective as in older patients. Acta Paediatr. 2015;104(1):e39-e44.

18. Van den Bruel A, Haj-Hassan T, Thompson M, Buntinx F, Mant D; European Research Network on Recognising Serious Infection investigators. Diagnostic value of clinical features at presentation to identify serious infection in children in developed countries: a systematic review. Lancet. 2010;375(9717):834-845. 
19. Jaeschke R, Guyatt GH, Sackett DL. Users' guides to the medical literature. III. How to use an article about a diagnostic test. B. What are the results and will they help me in caring for my patients? The Evidence-Based Medicine Working Group. JAMA. 1994;271(9): 703-707.

20. Crewe S, Rowe PC. Research and statistics: likelihood ratio in diagnosis. Pediatr Rev. 2011;32(7):296-298.

21. Chu H, Cole SR. Bivariate meta-analysis of sensitivity and specificity with sparse data: a generalized linear mixed model approach. J Clin Epidemiol. 2006;59(12):1331-1332, author reply 1332-1333.

22. Steinhauser $S$, Schumacher M, Rücker G. Modelling multiple thresholds in meta-analysis of diagnostic test accuracy studies. BMC Med Res Methodol. 2016;16(1):97.

23. Bulloch B, Bausher JC, Pomerantz WJ, Connors JM, Mahabee-Gittens $\mathrm{M}$, Dowd MD. Can urine clarity exclude the diagnosis of urinary tract infection? Pediatrics. 2000;106(5):E60.

24. Chaudhari PP, Monuteaux MC, Bachur RG. Microscopic bacteriuria detected by automated urinalysis for the diagnosis of urinary tract infection. J Pediatr. 2018;202:238-244.e1.

25. Chen L, Baker MD. Racial and ethnic differences in the rates of urinary tract infections in febrile infants in the emergency department. Pediatr Emerg Care. 2006;22(7):485-487.

26. Dobbs FF, Fleming DM. A simple scoring system for evaluating symptoms, history and urine dipstick testing in the diagnosis of urinary tract infection. J R Coll Gen Pract. 1987;37(296):100-104.

27. Felt JR, Yurkovich C, Garshott DM, et al. The utility of real-time quantitative polymerase chain reaction genotype detection in the diagnosis of urinary tract infections in children. Clin Pediatr (Phila). 2017;56(10):912-919.

28. Festo E, Kidenya BR, Hokororo A, Mshana SE. Predictors of urinary tract infection among febrile children attending at Bugando Medical Centre Northwestern, Tanzania. Arch Clin Microbiol. 2011;2(5):2.

29. Hoberman A, Chao HP, Keller DM, Hickey R, Davis HW, Ellis D. Prevalence of urinary tract infection in febrile infants. J Pediatr. 1993;123(1):17-23.

30. Kanegaye JT, Jacob JM, Malicki D. Automated urinalysis and urine dipstick in the emergency evaluation of young febrile children. Pediatrics. 2014;134(3):523-529.

31. Kartika I, Damanik MP, Soenarto SY. Diagnostic test of urine clarity in urinary tract infection. Paediatr Indones. 2006;46(7-8):170-173.

32. Lagos Zuccone R, Carter JS, Herrera Labarca P. Utilidad de una tira reactiva y del aspecto macroscópico de la orina para descartar la sospecha clínica de infección del tracto urinario en niños ambulatorios. Rev Chil Pediatr. 1994;65(2):88-94. [Article in Spanish]

33. Lizama CM, Luco IM, Reichhard TC, Hirsch BT. Infección del tracto urinario en un servicio de urgencia pediátrico: frecuencia y características clínicas. Rev Chilena Infectol. 2005;22(3):235-241. [Article in Spanish]

34. Mitiku E, Amsalu A, Tadesse BT. Pediatric urinary tract infection as a cause of outpatient clinic visits in southern Ethiopia: a cross sectional study. Ethiop J Health Sci. 2018;28(2):187-196.

35. Msaki BP, Mshana SE, Hokororo A, Mazigo HD, Morona D. Prevalence and predictors of urinary tract infection and severe malaria among febrile children attending Makongoro health centre in Mwanza city, North-Western Tanzania. Arch Public Health. 2012; 70(1):4.

36. Musa-Aisien AS, Ibadin OM, Ukoh G, Akpede GO. Prevalence and antimicrobial sensitivity pattern in urinary tract infection in febrile under-5s at a children's emergency unit in Nigeria. Ann Trop Paediatr. 2003;23(1):39-45.

37. Newman TB, Bernzweig JA, Takayama JI, Finch SA, Wasserman RC, Pantell RH. Urine testing and urinaçry tract infections in febrile infants seen in office settings: the Pediatric Research in Office Settings' Febrile Infant Study. Arch Pediatr Adolesc Med. 2002;156(1): 44-54.
38. Pylkkänen J, Vilska J, Koskimies O. Diagnostic value of symptoms and clean-voided urine specimen in childhood urinary tract infection. Acta Paediatr Scand. 1979;68(3):341-344.

39. Shaw KN, Gorelick M, McGowan KL, Yakscoe NM, Schwartz JS. Prevalence of urinary tract infection in febrile young children in the emergency department. Pediatrics. 1998;102(2):e16.

40. Tzimenatos L, Mahajan P, Dayan PS, et al; Pediatric Emergency Care Applied Research Network (PECARN). Accuracy of the urinalysis for urinary tract infections in febrile infants 60 days and younger. Pediatrics. 2018;141(2):e20173068.

41. Verbakel JY, Lemiengre MB, De Burghgraeve T, et al. Should all acutely ill children in primary care be tested with point-of-care CRP: a cluster randomised trial. BMC Med. 2016;14(1):131.

42. Zorc JJ, Levine DA, Platt SL, et al; Multicenter RSV-SBI Study Group of the Pediatric Emergency Medicine Collaborative Research Committee of the American Academy of Pediatrics. Clinical and demographic factors associated with urinary tract infection in young febrile infants. Pediatrics. 2005;116(3):644-648.

43. Craig JC, Williams GJ, Jones M, et al. The accuracy of clinical symptoms and signs for the diagnosis of serious bacterial infection in young febrile children: prospective cohort study of 15781 febrile illnesses. BMJ. 2010;340:c1594.

44. Bonadio WA, McElroy K, Jacoby PL, Smith D. Relationship of fever magnitude to rate of serious bacterial infections in infants aged 4-8 weeks. Clin Pediatr (Phila). 1991;30(8):478-480.

45. Shaikh N, Shope MF, Kurs-Lasky M. Urine specific gravity and the accuracy of urinalysis. Pediatrics. 2019;144(5):e20190467.

46. Gauthier M, Gouin S, Phan V, Gravel J. Association of malodorous urine with urinary tract infection in children aged 1 to 36 months. Pediatrics. 2012;129(5):885-890.

47. Chaudhari PP, Monuteaux MC, Shah P, Bachur RG. The importance of urine concentration on the diagnostic performance of the urinalysis for pediatric urinary tract infection. Ann Emerg Med. 2017; 70(1):63-71.e8.

48. Dickinson JA. Incidence and outcome of symptomatic urinary tract infection in children. Br Med J. 1979;1(6174):1330-1332.

49. Duong HP, Wissing KM, Tram N, Mascart G, Lepage P, Ismaili K. Accuracy of automated flow cytometry-based leukocyte counts to rule out urinary tract infection in febrile children: a prospective cross-sectional study. J Clin Microbiol. 2016;54(12):2975-2981.

50. Gorelick MH, Shaw KN. Clinical decision rule to identify febrile young girls at risk for urinary tract infection. Arch Pediatr Adolesc Med. 2000;154(4):386-390.

51. Gorelick MH, Hoberman A, Kearney D, Wald E, Shaw KN. Validation of a decision rule identifying febrile young girls at high risk for urinary tract infection. Pediatr Emerg Care. 2003;19(3):162-164.

52. Díaz MG, García RP, Gamero DB, et al. Lack of accuracy of biomarkers and physical examination to detect bacterial infection in febrile infants. Pediatr Emerg Care. 2016;32(10):664-668.

53. De $S$, Williams GJ, Hayen A, et al. Accuracy of the "traffic light" clinical decision rule for serious bacterial infections in young children with fever: a retrospective cohort study. BMJ. 2013;346:f866.

54. Hay AD, Whiting P, Butler CC. How best to diagnose urinary tract infection in preschool children in primary care? BMJ. 2011;343: d6316.

55. Zorc JJ, Kiddoo DA, Shaw KN. Diagnosis and management of pediatric urinary tract infections. Clin Microbiol Rev. 2005;18(2):417-422. 